\title{
The Maximum Scale Analysis of PV Generation Growth based on Power Grid Development
}

\author{
Huang Zonghong ${ }^{1}$, Long Wangcheng ${ }^{2,},{\mathrm{Xiang} \mathrm{Li}^{1}, \mathrm{Xu} \text { dongjie}}^{2}$, and Sun Zhe ${ }^{2}$ \\ ${ }^{1}$ State Grid Ningxia Electric Power Corporation Limited Economic \& Technical Research Institute, 750000 Middle Road of Baohu, \\ Yinchuan China \\ ${ }^{2}$ China Electrical Power Planning \& Engineering Institute, Energy Research Institute, 100120 No.65 Ande Road, Xicheng District, \\ Beijing, China
}

\begin{abstract}
Since 2010, photovoltaic (PV) was growing rapidly for policy guidance in China. The largescale PV electricity generation had a great influence on the power grid operation because of the change of the power supply layout. How to analyse the influence is an important matter to power system development. The analysed results will decide the trends of the PV electricity generation in future. Therefore, the Coordination analysis of PV generation growth is crucial to those developments. In this paper, the reasonable plant scale arrangement was discussed based on the difference between peak and valley of power system.
\end{abstract}

\section{Introduction}

With global climate warming becoming more and more concerned, the worldwide eventually factored the carbon emission into ecological environment. The percentage of fossil-fired energy decreased for the 21st century due to renewable energy explosive growth [1]. As report by EPPEI, the total energy consumption of china in 2018 was 4.64 billion SCE, an increase of 3.3 percent over the previous year. The proportion of clean energy in the total consumption had risen to $22.1 \%$, and the proportion of non-fossil energy in the total consumption arrived $14.3 \%$. The growth was largely driven by wind and solar PV, which saw annual average growth rates of $21 \%$ and $43 \%$ between 2010 and 2018, the proportion of wind energy and PV in consumption arrived $2.4 \%$ and $1.2 \%$ respectively. The capacity electrical plants was 1.9 billion kilowatts, the combustible fuel plants accounted for $60.2 \%$ of total gross electricity production, nuclear plants $2.4 \%$, hydroelectric plants $18.5 \%$, PV $9.2 \%$ and wind $9.7 \%$. The annual capacity of China in 2018 was 7 trillion kilowatt-hour, the combustible fuel plants accounted for $60.2 \%$ of total gross electricity production, nuclear plants $2.4 \%$, hydroelectric plants $18.5 \%$, solar PV 9.2\% and wind 9.7\%. [2]

The sharply development of distributed PV electricity generation produced a profound influence to power gird, which is not same as the centralized PV electricity generation. Before the centralized one construction and operation, the power interconnection systems for above $110 \mathrm{kV}$ grade had been design details, and the impact of power station to power system had been analysed clearly. But the distributed PV electricity generation was connected to $10 \mathrm{kV}$ or lower grade. The power interconnection system was oversimplified. So the impact of distributed PV electricity generation does not discuss specialized, this question would be analysed based on simulation calculation.

\section{Power grid operation mode}

The normal operation mode was analysed firstly to identify the impact of the distributed PV electricity generation. The power transmission structure had been analysed to reflect the transferring characteristics from power plant to consumer [3-4]. In china, the $220 \mathrm{kV}$ power grid was the backbone network in 1981, and then, $500 \mathrm{kV}$ power grid were established as main network in following 30 years, $500 \mathrm{kV}$ power grid covered provinces or regions. Nowadays, the $1000 \mathrm{kV}$ UHV power grid and $\pm 800 \mathrm{kV}$ UHVDC project were successes. Synchronous UHV power grid will cover the East, North and Middle China in 2020 [5-6]. Therefore, the power grid is made up of different voltage grades.

\subsection{Traditional power grid operation}

The traditional electric energy was thermal power and hydropower in China. The installed capacity of each generation exceeds 200MW almost, which coupled with high voltage level. Generally, the interconnect grade was above $220 \mathrm{kV}$. However, the loads were mostly connected to a low voltage grade, such as $10 \mathrm{kV}$ or lower one. In the circumstances, the power flow usually transfers from high voltage to low voltage at the hierarchal structure. The large power plants generate electrical energy, which are transmitted to high voltage grade. A part of the electrical energy is transmitted to

\footnotetext{
* Corresponding author: longwangcheng@163.com
} 
load centre of power system, and then that is transferred to low voltage grade by transformers. Another part of electrical energy is transmitted to other power grid by transmission access. Correspondingly, the electrical energy might be transmitted into this power grid from other one. The lower voltage grades accept the electricity purely throughout the year.

\subsection{Power system load characteristics}

The most of load was connected in lower voltage grade, such as $110 \mathrm{kV}, 10 \mathrm{kV}$ and $038(0.22) \mathrm{kV}$. The daily load curve of the province A was collected on primary equipment. The load curves have two load peaks in a day, one peak appears at 8:45, and another peak appears at $18: 45$, the curve is shown as Fig.1.The load a curve of $110 \mathrm{kV}$ transformer substations is be similar to provincial grid one shown as Fig.2. However, the load curve of $10 \mathrm{kV}$ transformer substations fluctuated persistently, which is shown as Fig.3.

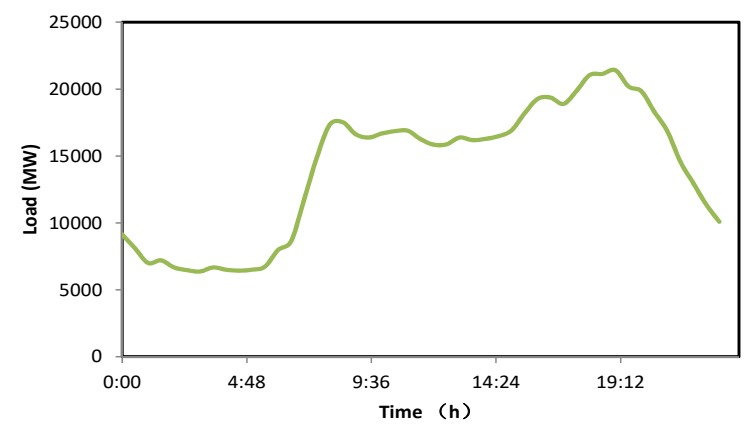

Fig. 1.The load curve of Provincial A grid .

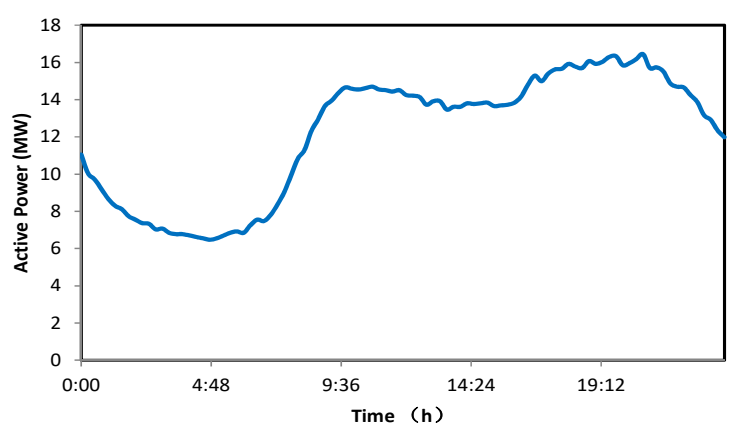

Fig. 2. The load curves of $110 \mathrm{kV}$ transformer substations .

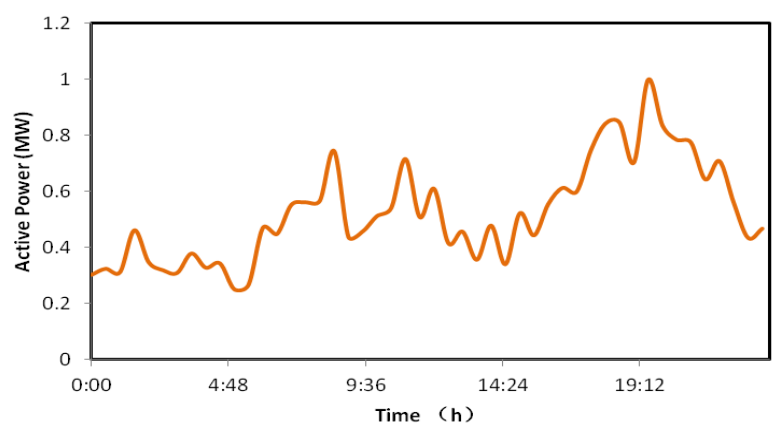

Fig. 3. The load curve of $10 \mathrm{kV}$ transformer substations .

\subsection{Resource condition}

The sharply development of distributed PV electricity generation produced a profound influence to power gird, which is not same as the centralized PV electricity generation. The power interconnection systems for above $110 \mathrm{kV}$ grade had been design in detail, and the impact of power station to power system had been analysed clearly. But the distributed PV electricity generation was connected to $220 \mathrm{~V}, 380 \mathrm{~V}$ or $10 \mathrm{kV}$, the power interconnection system was oversimplified, the impact of distributed PV electricity generation does not discuss detailed, this question would be analysed based on simulation calculation.

\section{PV Electricity generation}

\subsection{Interconnection of the PV Power generation}

What level grid to which the distributed PV electricity generation connected is depended on the scale of installed capacity and the native power grid structure.

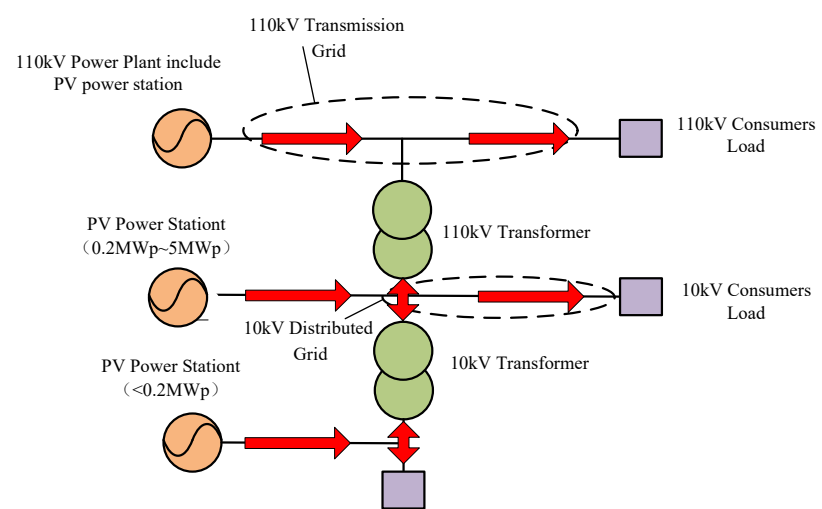

Fig. 4 The distributed PV electricity generation connecting to power grid.

The power station whose installed capacity exceeded $0.2 \mathrm{MWp}$ is proposed to connect into power grid with 10 $\mathrm{kV}$. The power station whose installed capacity exceeded $10 \mathrm{MWp}$ is proposed to connect into power grid with $110 \mathrm{kV}$. Therefore, there are three connection modes, and those were shown in Fig.4.

\subsection{Output Curves of PV generation}

The output power of PV electricity generation was affected by many influencing factors. The weather was the most critical factor to output power because of the sunshine being the energy source of PV electricity generation. The output power curves of a 3.5 MWp PV station under three different weather conditions were shown in Fig. 5 [6-9]. The output power curves on sunny days were a smooth parabolic which was proportionate to solar radiant energy. However, the output power carves was a nonlinear wave on cloudy days for the sunshine being shaded by clouds. On overcast days, the output power discounted for the PV generation was covered by a bank of thick clouds in whole day. The output power was able to cover others condition, 
although the output power curves at different weather had great variability. Therefore, the output power characteristics at sunshine day were used to analyse the impact.

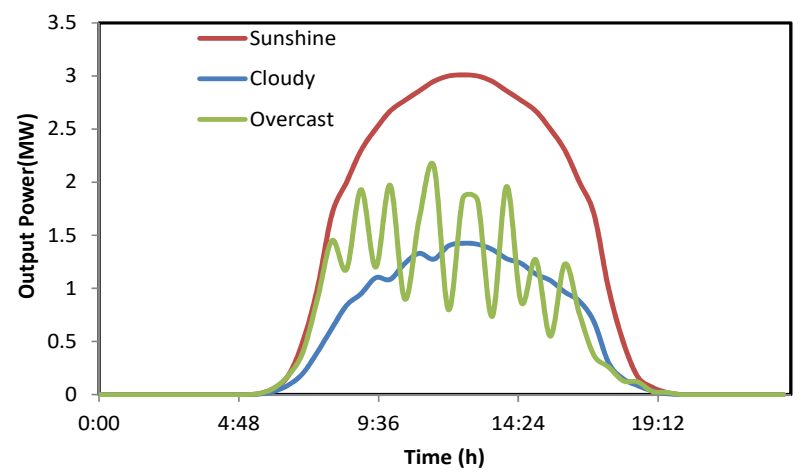

Fig. 5. the output power of a $3.5 \mathrm{MWp}$ PV generation under three weather conditiongs.

\section{Impact Analysis}

The interconnect position of PV power station is described in Fig.4. With the distributed PV power development, the output power from PV generation increase correspondingly, and the power flow in distributed power grid has changed for new power pumped into. At the same time, the load characteristics are variation for power generated at daytime. Furthermore, the coordination evaluation about the distribution grid is needed to be adjusted. In this section, the impact of distributed PV generation is analysed as following.

\subsection{Load Flow Analysis}

With the PV electricity generation connected into power grid, the output power is absorbed by local grid firstly. Meanwhile, the electricity supplies from higher voltage grid decreased, which are counteracted local load by output power of PV station. The load power of transformer which the lower voltage system contain distributed PV station is equal to actual load subtract the output, as in

$$
L_{\mathrm{T}}(\mathrm{t})=L_{\mathrm{A}}(\mathrm{t})-P_{\mathrm{s}}(\mathrm{t})
$$

In which, $L_{\mathrm{T}}$ is load power of transformer which the lower voltage system contained distributed PV station, $L_{\mathrm{A}}$ is actual load of the system, $P_{\mathrm{s}}$ is the output of the distributed PV station, $\mathrm{t}$ is the time in a day.

\subsection{Experimental Analysis}

Generally, a poor village in China just has a transformer to supply the power. According to the poverty relief policy, a poor village is required to construct $300 \mathrm{~kW}$ to $500 \mathrm{~kW}$ PV power station, meanwhile, someone construct the PV power station on themselves roof or farmland. Therefore, the capacity of PV generation to analyse is $300 \mathrm{~kW}$ and $600 \mathrm{~kW}$. The load curves with different PV generation capacity are simulated based on the typical transformation $\mathrm{C}$ load characteristics and PV output characteristics, and it is shown in Fig.6. The load is less than zero when the PV capacity exceeds $300 \mathrm{~kW}$. The active power became negative, which means the transformer change to step-up transformer in midday. In that case, the difference between daily peak and valley load became to $1.57 \mathrm{MW}$, which was one and half times as big as one with $0 \mathrm{~kW}$ PV generation.

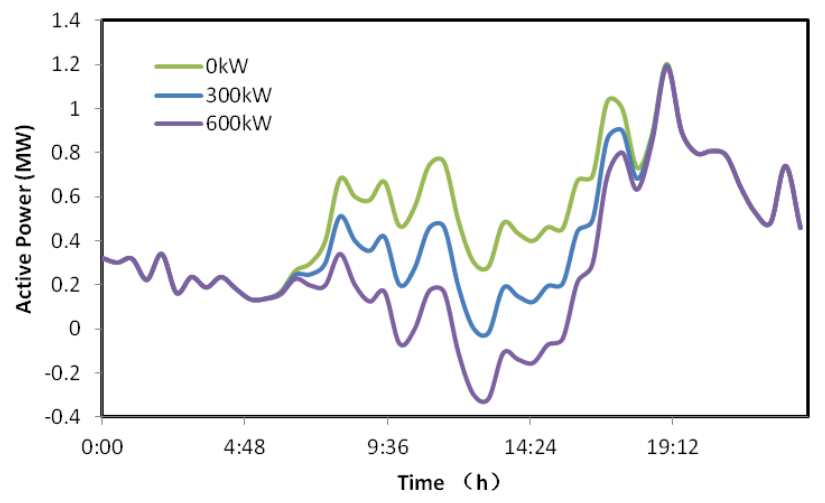

Fig. 6. The load curve of $10 \mathrm{kV}$ transformer with $0 \mathrm{~kW}, 300 \mathrm{~kW}$ and $600 \mathrm{~kW}$.

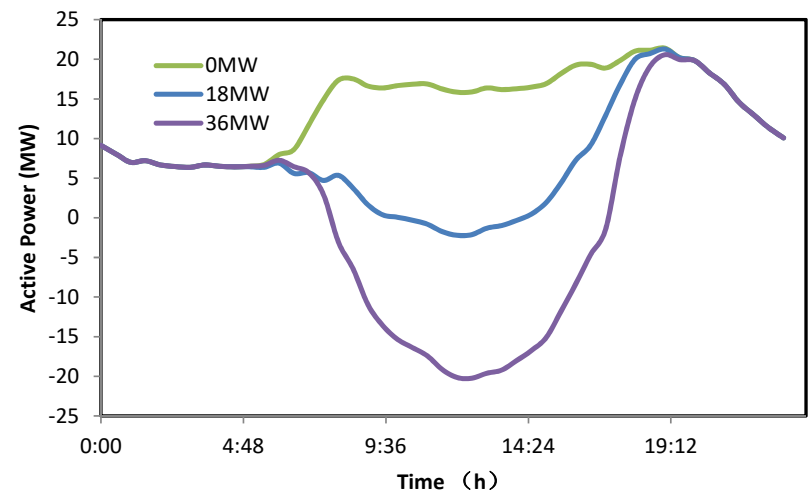

Fig. 7. The load curve of $110 \mathrm{kV}$ transformer with $0 \mathrm{~kW}, 18 \mathrm{MW}$ and $36 \mathrm{MW}$.

The load curves of $110 \mathrm{kV}$ transformer with different PV generation capacity are simulated, and it is shown in Fig. 7. The load is less than zero when the PV capacity exceeded 18MW, and then, the active power became negative, which means the transformer change to step-up transformer in midday too. When the PV capacity exceeded $36 \mathrm{MW}$, the reversed active power reaches to 20MW. In that case, the difference between daily peak and valley load becomes $40.8 \mathrm{MW}$, which was 2.7 times as big as one with $0 \mathrm{MW}$ PV generation.

The installed PV generation capacity is rather difficult to forecast. Especially, the distributed PV station is independent of direct government control. It is different to the centralized PV station, which the project before construction must get government approval. The distributed PV station is exploding recently. Therefore, the installed PV generation capacity of $0 \mathrm{MW}, 3000 \mathrm{MW}$, $6000 \mathrm{MW}$ and $12000 \mathrm{MW}$ at province $\mathrm{A}$ is supposed, the PV permeability is $0 \%, 15 \%, 30$ and $60 \%$, respectively. 
The load curves of province A with different PV generation capacity are shown in Fig. 8. The difference between daily peak and valley load decreases firstly until the installed PV generation capacity excel 6000MW. The revenue dropped by $140 \mathrm{MW}$. However, the difference between daily peak and valley load amplify by a staggering $2244 \mathrm{MW}$ with the PV generation capacity increasing.

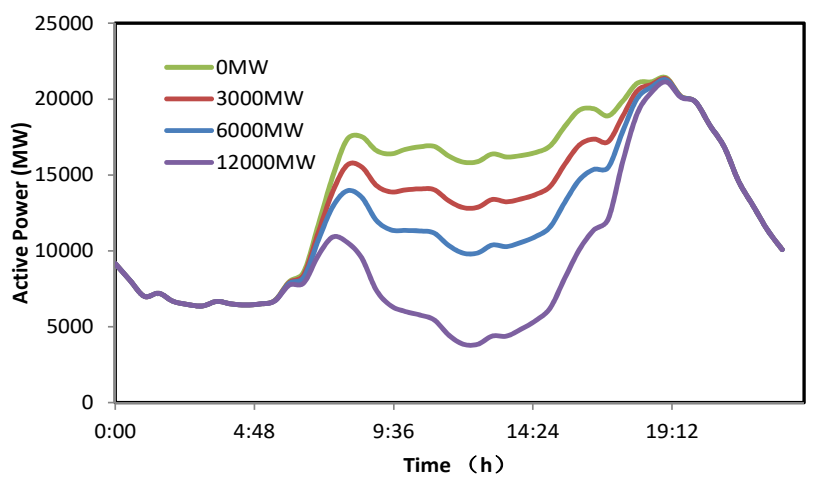

Fig. 8. The load curve of province A with $0 \mathrm{MW}, 3000 \mathrm{MW}$, $6000 \mathrm{MW}$ and $12000 \mathrm{MW}$.

\section{Discussions}

\subsection{Distribution network}

The operation and flow direction of distribution network was effect seriously by the distributed PV generation. The network structure become complexity because of the control of communication facilities increased in some sense. The distribution network changes to active electric network with the distributed generation appearing. The native load is supplied by local PV generation handy [910]. Those reduced the transmission demand from higher voltage grade to lower one. That will reduce the loss in power transmission. Moreover, the power flow in midday might change the direction top. As a result, the construction and investment of distribution network should take into account the transmission demand of network, which includes positive and negative power flow. The traditional invest experience which is fully meet the demand of local might be not applicable. The investment about satisfy power supply should be cautious in distributed PV power station fast-growing regions, the invest direction must pay close attention to absorption and delivery of the PV power.

\subsection{Power system}

The most important impact of distributed PV generation to power system is the load charities. A certain scale PV generation capacity will decrease that difference peak valley, which is good for power system operation. However, the capacity of PV generation keeps growing, the load character become worse, and the difference peak valley increase directly. Those lead to the cycling problem in the power grids, which becomes more and more pronounced. Hence, the constructed scale of PV generation in a system should be planned based on difference between peak and valley and the shift peak load capacity.

It is noteworthy that the coordination among multiple power grid. To reduce the transmission loss, the PV generations should not concentrate on a grid, which designed as distributed system. Those avoid the PV power transmits far away from PV generations concentration area to load area. The investment and planning of power station should arrange balanced in different area.

\section{CONCLUSION}

The power grid operation mode was proposed to analyse the influence of fast-grown distributed PV electricity generation. The output character of PV electricity generation and load curve was investigated. The simulation based on load and power had been completed for reflect the effect of PV electricity generation. The investment advice was suggested on distribution network and power system respectively. In power system planning and investment, $30 \% \mathrm{PV}$ permeability was maximum limit which presented by the difference between daily peak and valley load at province A.

\section{References}

1. EPPEI, China energy anuual report 2018, China Electric Power Press, (2018)

2. The editorial committee, China Electric Power Yearbook 2018, China Electric Power Press, (2018).

3. Long W, Han F, Xiao J and Wang X. The Study of Adequacy Evaluation Method of Power Scale, Electro. App., 34, 5, (2015).

4. Long W, Wang X, Peng D, Zhang P and Han F, The Adequacy Discrete Analysis Based on Hierarchical Structure of Power Grid. IEEE POWERCON, (2014)

5. Liu Z. The Ultra-high Voltage Grid. Economic Press of China, (2005)

6. Ding D. the Development of Modern Power Grid and Security, Tsinghua University Press, (2012)

7. Pyo G, Kang H, and Moon S. A new operation method for grid-connect PV system considering voltage regulation in distribution system, IEEE PES GM, Pittsburgh.PA, (2008)

8. Notton G, Cristofari C, Muselli M, Poggi P and Heraud N. Hourly solar irradiations estimation :from horizontal measurements to inclined data. ISEIMA, (2006)

9. $\mathrm{Yu} \mathrm{J}$, Chi F, Xu K, Li S, Analysis of the Impact of distributed generaion on powe grid, Proceedings of the CSU-EPSA.24, (2012)

10. Shen X, Cao M, Reasearch on the Influence of Distributed Power grid for Distribution Network. Tran. China Elec. Soc., 30, ( 2015) 